\title{
INFLUENCE OF FRICTION CRUSH WELDING TOOL PROFILES ON THEWELDABILITY OF COMMERCIAL ALUMINUM TUBES
}

\section{HAMMAD T. ELMETWALLY, NAGUIB G. YAKOUB, MOHAMED N. ELSHEIKH, AYMAN A. ABD- ELTWAB, MAHMOUD E. ABDULLAH}

Department of Mechanical Engineering, Beni-Suef University, Beni-Suef, Egypt

\begin{abstract}
Internal flash defect one of the common welding defects appear after welding tube to tube by conventional friction welding techniques. Internal flash defects classified as a drawback when we use the inner diameter of welded tubes to transfer liquids or gases. This study focusing on the welding tube to another tube without internal flash defect. A new welding technique called orbital friction crush welding $(\mathrm{OFCW})$ was used for this investigation. The OFCW tool has disk geometry with a specific groove. The groove designed in the tool profile to crush the edges of the joint. Three tool grooves $V$-groove, trapezoidal groove, and concave groove were considered as the main effective welding parameters for crushing the material. The material was used commercial tubes of aluminum. The tubes have 60 mm outside diameter and $3 \mathrm{~mm}$ wall thickness. The heat treatment process was performed to standardize the tubes besides forming the edges to flange without cracks. Several working parameters such as the tool welding profile, the flange ratio, and the rotation speed were considered. The results of experimental works carried out the relationship between the welding parameters and both welding temperature and welding strength. The maximum welding strength was carried by trapezoidal profile groove comparison with other grooves.

KEYWORDS: Solid-State Welding, Friction Welding, Friction Crush Welding, Tube Welding, Aluminum Tubes
\end{abstract}

Received: Jun 05, 2020; Accepted: Jun 25, 2020; Published: Jul 30, 2020; Paper Id.: IJMPERDJUN2020531

\section{INTRODUCTION}

Industrial applications of friction welding increase in recent years; It uses in electronic packages, engines, fuel tanks, tubes, pipelines, and other manufacturing applications. This development return to the past investigations showed that fusion welding caused many problems in the welding zone during joining some series of light metals like aluminum alloys [1-3]. Friction welding principle depending on two main factors, friction heat, and compressive forces [4]. Frictional heat produced as a result of mechanical energy whatever moving or rotating while compressive forces are used for bonding. Friction welding has two groups classified as the relative motion of the work piece and the relative motion of the tool [5]. Both friction welding groups produced success specimens during welding bars, plates, and sheet metals [6-8], However, there are many annually articles present and discuss these types of issues concerned with improving or developing friction welding processes and friction welding parameters. Ebrahimzadeh et al. [9] studied the various parameters of orbital friction stir welding process on mechanical properties and microstructure of heat treatable aluminum alloys AA5456-H321 and AA5456-O. The optimum welding parameters occur at the tool rotation speed $900 \mathrm{rpm}$ and travel speed $45 \mathrm{~mm} / \mathrm{min}$. In tube/pipe welding, the relative motion of the tool is a common friction welding type for instance; Ismail et al. [3] carried out a study on weldability of aluminum alloy 6063 pipes by friction stir welding process. The aluminum Pipes defined by $89 \mathrm{~mm}$ outer diameter and $5 \mathrm{~mm}$ wall thickness. The tool rotated on three levels of speeds $1000 \mathrm{rpm}, 1300 \mathrm{rpm}$, and $1600 \mathrm{rpm}$. The experimental work results of aluminum pipes 6063 showed the heat generation increases with 
increasing the tool rotation speed. Other investigations on aluminum alloys 6063 were carried the properties of friction welding by using orbital clamping unit system (OCUS) [10,11]. The OCUS defined as a system to rotate the work piece parts at the same time around its axis by mandrel/ shaft connected with external motor.

From previous works, we noted some limitations in tube/ pipe welding related to friction welding category for instance; the common defect that appears after welding by the relative motion of the work piece is an external and internal flash. External flash easy to remove by machining processes, but internal flash is hardly removed. In the relative motion of the tool, tubes, and pipes usually welded by orbital friction stir welding. This technique confined the external and internal flash defects, but other defects related to orbital friction stir welding process may appear such as a large hole (keyhole) construct in the work piece at friction stir welding tool eject. Another way in the relative motion of the tool, there is a new welding technique called friction crush welding (FCW). FCW (i.e. friction squeeze welding) is a new patent, beginning applied on thin sheet metal with the same thickness and same material [4,5]. FCW so far FSW technique; it used the nonconsumption external tool but the difference between them in tool geometry. In FSW, the tool has probe and shoulder while in FCW the tool has disk geometry with specific groove design for crushing additional material. Recent works in FCW focused on the relationship between bond strength of welding joint (i.e. ultimate tensile strength of welded joint) and the base metal strength $[4,5],[12,13]$.

Consequently, this study is a new investigation for joining similar tubes without internal flash by a combination of friction welding parameters. This technique called orbital friction crush welding which regarded as the development of conventional friction welding and FSW used for joining tubes or pipes. The welded joints prepared with flanged edges and the tool profile has a specific groove. Different welding parameters are considered to determine the optimum tool profile that improves joint efficiency.

\section{EXPERIMENTAL WORK}

\subsection{Principle of Orbital Friction Crush Welding}

Orbital friction crush welding tool has disk geometry with a specific groove. The groove of the tool is selected to be concave, trapezoidal, or V shape. Figure (1) is shown the principle of the OFCW technique. The tubes have flanged edges then fixed on the mandrel by bolts. Two sources of motions are used, one used for rotating the tool, and the other used to rotate the packing mandrel. The tool rotates against the work pieces then moved (radial motion) until the tool shoulder touch with the flanged diameter of the tube.

Figure 1: Schematic diagram of OFCW process, $\mathrm{A}$ is the $\mathrm{OFCW}$ tool, $\mathrm{B}$ is the tool groove, $\mathrm{C}$ is the base metal tube, $\mathrm{D}$ is the additional flanges, $\mathrm{E}$ is the mandrel of work pieces, $\mathrm{F}$ is the shaft for driven the tool, $\mathrm{G}$ is a pin to fix the tube on the mandrel, $\mathrm{H}$ is the direction of rotational motion of the tool, and $\mathrm{I}$ is the direction of rotational motion of the work pieces. 


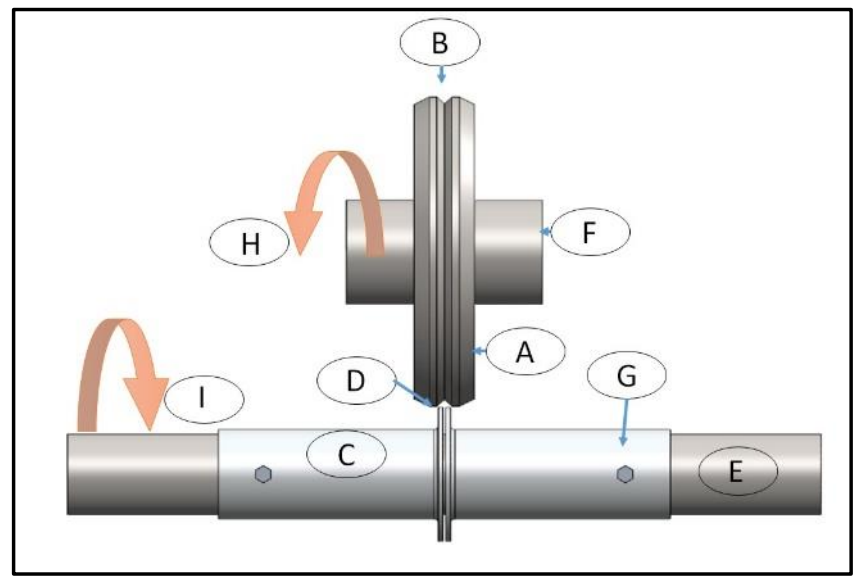

Figure 1

\subsection{Material and Experimental Setup}

The metal was used as a commercial aluminum tube. The tubes defined by outside diameter 60 mm and tube wall thickness $3 \mathrm{~mm}$. The tubes machined to $150 \mathrm{~mm}$ as a length of one side of the joint. The annealing process was performed on the tubes at $450^{\circ} \mathrm{C}$ for 2 hours to standardize the tubes in addition to increase the base metal ductility. The mechanical properties of this aluminum alloy carried out by ASTM-E8M sub size geometry specimen. Four samples are used in the tensile test to determine the mechanical properties of the work piece material given in the table (1). The hardness of aluminum also measured before and after annealing by micro Vickers hardness tester, model number 1600-4981. After annealing processes, the two tube pieces are formed to flange shape at their ends of the welding side by a simple spinning tool at room temperature. Figure (2) is shown the OFCW setup. A continuous drive source (lathe machine) which used to rotate the work pieces against the tool as a friction heat source. The universal lathe was used as a general-purpose which has a motor power $13 \mathrm{KW}$ and 24 rotational speeds ranging from $8 \mathrm{rpm}$ to $1000 \mathrm{rpm}$. The external motor has $3 \mathrm{KW}$ and a fixed rotational speed of $1420 \mathrm{rpm}$ is used to rotate the tool against the direction of the work pieces. According to previous works, a set of rotation speeds were selected to rotate the work pieces for frictional heat. The temperature was measured for all welded specimens by thermocouple type K. The thermocouple was connected directly with Digital Multimeter to get the temperature value directly. The thermocouple was calibrated on boiled oil before measuring the welding temperature to eliminate the measuring error.

Table 1: Mechanical Properties of Aluminum Alloy

\begin{tabular}{|c|c|c|c|c|}
\hline Aluminum & Proof Stress or 0.2 \% YS (MPa) & UTS (MPa) & Elong. \% & HV \\
\hline As received & 224 & 245 & 11.69 & 78 \\
\hline After annealing & 81 & 118 & 31.11 & 41 \\
\hline
\end{tabular}

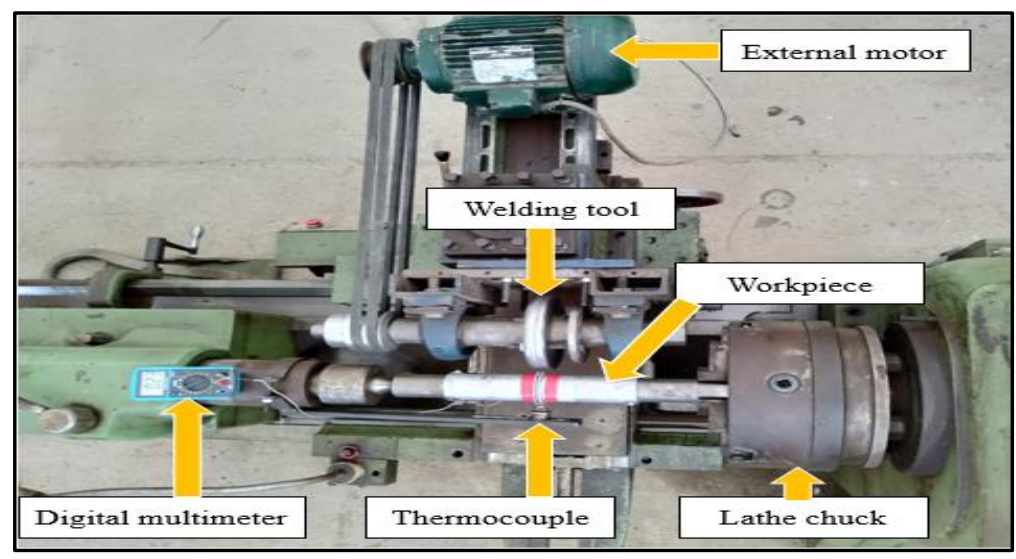


Figure 2: Top View for the Experimental Setup of OFCW Process.

\section{RESULTS AND DISCUSSIONS}

\subsection{Welded Tubes Products}

The experimental work array designed as $(3 \times 3 \times 4)$ i.e. 36 specimens carried by three tool profiles, three flange ratio, and four rotational speeds. The tool profiles were used V-profile, trapezoidal profile, and Concave profile. The flange ratios were used at $1.25,1.35$, and 1.45 . The rotational speeds were used 500, 630, 800, and $1000 \mathrm{rpm}$. Figure (3) is shown some of the product weldments by OFCW tools at the same flanging ratio, different mandrel speeds, and different tool profiles.

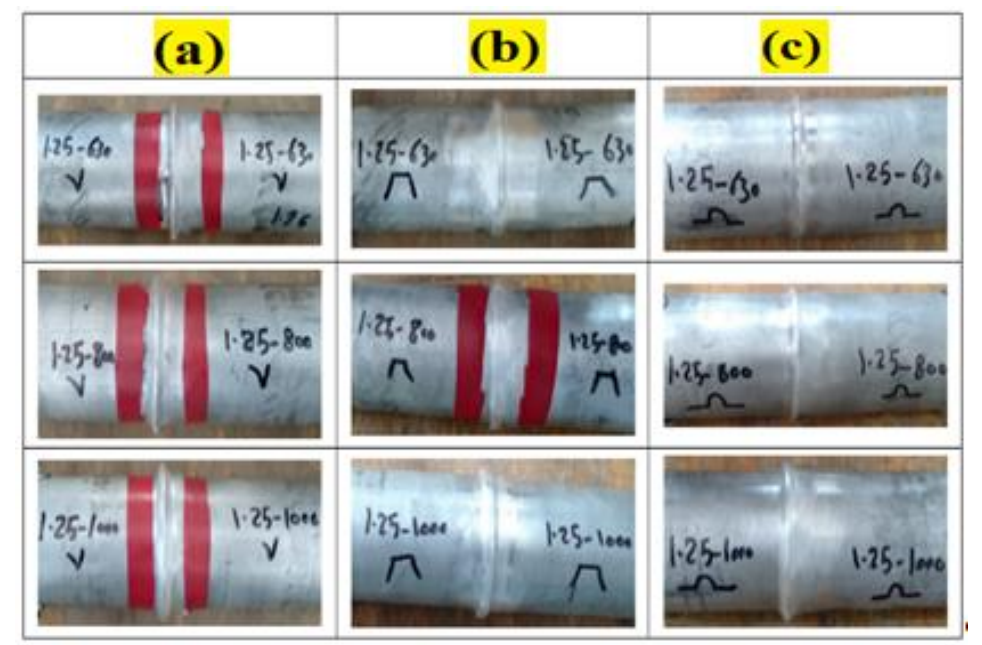

Figure 3: Set of Welded Specimens by OFCW Technique (A) VProfile, (B) Trapezoidal Profile, (C) Concave Profile.

\subsection{Effect of Rotational Speed on the Welding Temperature at Different Flange Ratio}

Figure (4) is shown the results of measured temperature at different welding conditions such as rotational speed, tool profiles, and flange ratio. When used the welding tool with V-profile shape as illustrated in Figure (4-a); the higher temperature values were recorded at flange ratios 1.25 comparison with the other flange ratios (1.35 and 1.45). The peak temperature value was recorded at $1000 \mathrm{rpm}$ which reached $249^{\circ} \mathrm{C}$. The regression factor of the trend of more than $91 \%$ for each flange ratio indicated a higher correlation between rotation speed and welding temperature. Figure (4-b) is shown the relation between rotational speed and temperature by using a trapezoidal profile shape. The observation indicated that higher temperature was recorded due to high contact profile length with the work piece comparison the peak temperature generated by $\mathrm{V}$ - profile. The maximum temperature measured by trapezoidal profile reached to $270^{\circ} \mathrm{C}$ at rotational speed $1000 \mathrm{rpm}$ and flange ratio 1.25. The last group shows the relation between temperature measured and rotational speed by concave profile shape as shown in Figure (4-c). Higher temperature values were recorded at flange ratio 1.25 with different levels of rotational speed. The peak temperature measured by the concave profile up to $268^{\circ} \mathrm{C}$.

For all flanging ratios or all tool profiles; the recorded temperature values are in proportion to the rotational speeds. In OFCW or other types of friction welding, the mechanical power which mainly depends on rotational speed is converted to a thermal power that raises the welding temperature. The present results are consistent with references [5,9,14]. It was demonstrated [15] that for several aluminum alloys a general relationship between maximum welding temperature $\left(\mathrm{T}\right.$, $\left.{ }^{\circ} \mathrm{C}\right)$ and friction welding parameters $(\omega, v)$ can be explained by: 


$$
\frac{T}{T_{m}}=K\left(\frac{\omega^{2}}{v * 10^{4}}\right)^{\alpha}
$$

Where, the exponent $\alpha$ was reported to range from 0.04 to 0.06 , the constant $\mathrm{K}$ is between 0.65 and 0.75 , and $\mathrm{T}_{\mathrm{m}}\left({ }^{\circ} \mathrm{C}\right)$ is the melting point of the alloy. The above relation denotes in general that the welding temperature is directly proportioned to the rotational speed.

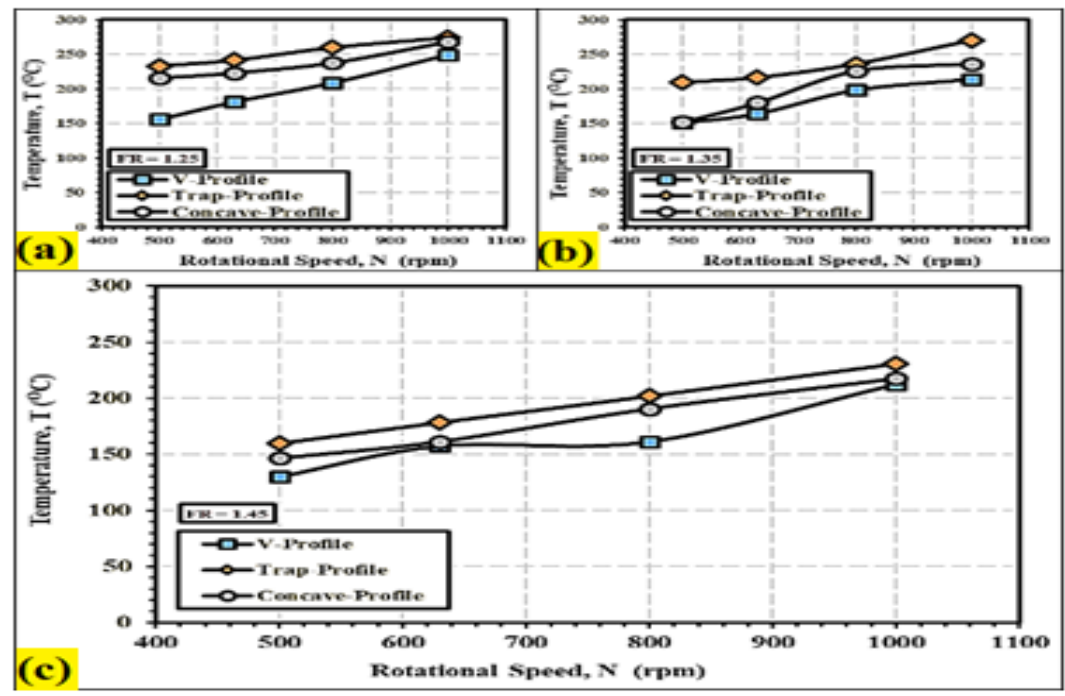

Figure4: Effect of Rotational Speed on the Welding Temperature at Different Profile Tool for $(\mathrm{A}) \mathrm{FR}=1.25$, (B) $\mathrm{FR}=1.35$, and $(\mathrm{C}) \mathrm{FR}=1.45$.

\subsection{Effect of Tool Profile on the Welding Temperature at the Different Rotational Speed}

Welding temperature by different profile shapes was observed at different rotational speeds as illustrated in Figure (5). In Figure (5-a), the welded specimens at the flange ratio 1.25. The maximum temperature value was recorded by $\mathrm{V}$-profile $249^{\circ} \mathrm{C}$ at rotation speed $1000 \mathrm{rpm}$ while the lowest was $156^{\circ} \mathrm{C}$. The second tool was the trapezoidal profile that recorded $274^{\circ} \mathrm{C}$, its relatively higher temperature value when compared to V-profile. By using the concave profile, it gave the results overhead the V-profile but it lowest than tarp-profile. Figure (5-b) is shown the welding temperature of the tool profiles at the flange ratio 1.35. At a different level of rotation speed $500 \mathrm{rpm}$ and $630 \mathrm{rpm}$, there is not a large noticeable change of the temperature generated by both V-profile and concave profile except at $800 \mathrm{rpm}$ and $1000 \mathrm{rpm}$. Figure (5-c) depicts the relation between the tool profile and welding temperature at different rotation speeds which the specimens have flange ratio 1.45. The peak temperature up to $230{ }^{\circ} \mathrm{C}$ by tarp-profile in which the V-profile and concave profile carried $212^{\circ} \mathrm{C}$ and 217 ${ }^{\circ} \mathrm{C}$ respectively.

The overall experiment results indicated the highest temperature is obtained as $274^{\circ} \mathrm{C}$ in the case of trapezoidal profile at rotation speed $1000 \mathrm{rpm}$ and flange ratio 1.25 . The heat generated due to the friction force in proportion to the area of contact between the tool profile and the flange of the tube. The maximum contact area is expected in the case of the trapezoidal profile. 


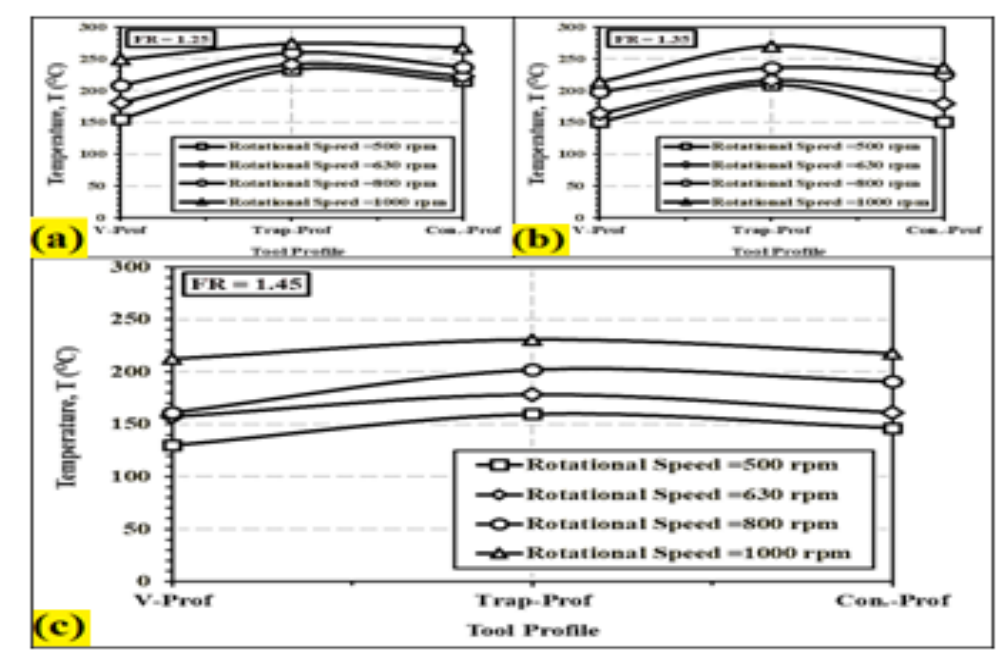

Figure 5: Effect of Tool Profile on the Welding Temperature at Different Rotational Speed for(A) FR=1.25, (B) $F R=1.35$, and (C) $F R=1.45$.

\subsection{Effect of Rotational Speed on Welding Strength at Different Flange Ratio}

The joint strength is the major factor that conducts the weldability of tube joints. The ratio between the welded joint strength to the tube strength conduct the efficiency of the joint. The influence of the tool profile on the joint strength is shown in Figure (6) (a, b and c). The tool profile has a noticeable influence on the strength values. Figure (6-a) is shown the relation between rotational speed and welding strength with V-profile shape. At rotation speeds $500 \mathrm{rpm}$ and $630 \mathrm{rpm}$, low welding strength occurred due to low heat input as a result of low rotation speed. At rotation speed $800 \mathrm{rpm}$, the welding strength improved which recorded 17.7 MPa with flange ratio 1.25, in addition, 12.9 MPa at flange ratio 1.35. At rotation speed 1000 rpm, high welding strength recorded comparison with other rotation speeds. The maximum welding strength occurred by $\mathrm{V}$ profile was $26.5 \mathrm{MPa}$ at rotation speed $1000 \mathrm{rpm}$ and flange ratio 1.25. Figure (6-b) is shown the values of strength recorded by trapezoidal profile shape. High strength values were recorded at different rotation speeds except for the rotation speed $500 \mathrm{rpm}$. At flange ratio 1.25, high welding strength was recorded comparison with flanges ratio 1.35 and 1.45 . This signified that the amount of heat generated by rotational speeds does not reach the melting temperature of base metal or slightly below. Figure (6-c) is shown the strength values carried by the concave profile shape. In this group of weldments, low welding strength measured at flange ratio 1.45 due to low heat input. At flange ratio 1.35, the welding strength up to $21 \mathrm{MPa}$ with rotation speed $1000 \mathrm{rpm}$. At flange ratio 1.25, the strength of the joints improved especially at rotation speed $1000 \mathrm{rpm}$ which recorded 44.22 $\mathrm{MPa}$. The results of overall welded specimens indicated the trap-profile gives the highest strength value than the concave profile while the V-profile produces the weakest joint. 


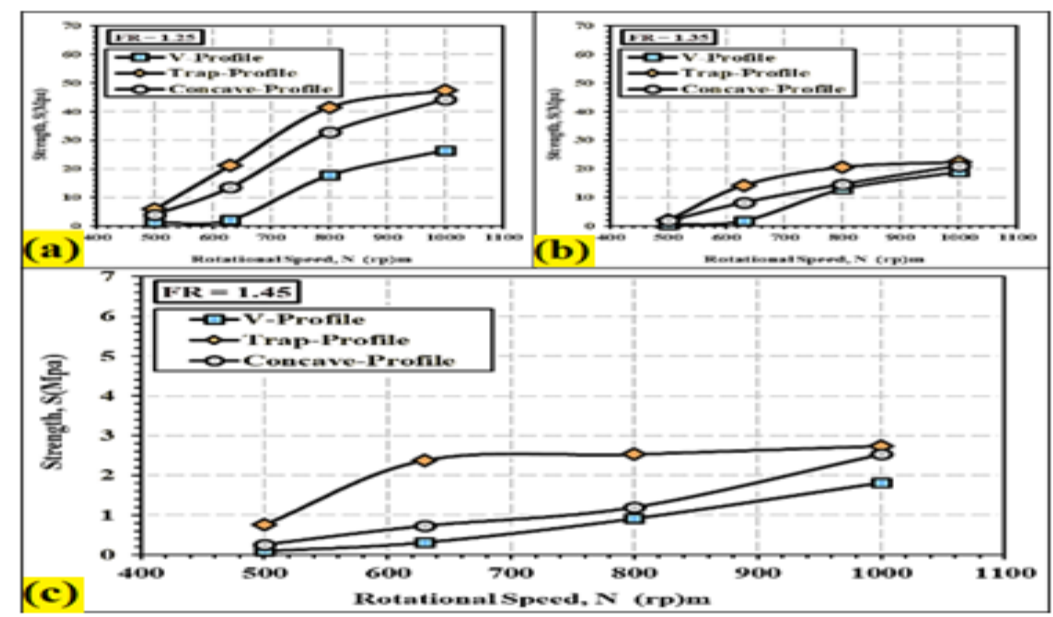

Figure 6: Effect of Rotational Speed on the Joint Strength at Different Profile Tool for (A) FR=1.25, (B) FR=1.35, and (C) $F R=1.45$.

\subsection{Effect of Tool Profile on Welding Strength at the Different Rotational Speed}

The relation between the OFCW tool profiles and welding strength as illustrated in Figure (7). Three tool profiles V-profile, trap-profile, and concave profile named as A, B, and C. Figure (7-a) is shown four levels of the rotational speed at flange ratio 1.25. Trap-profile (B) recoded high strength values compared with the concave profile (C) and V-profile (A). At different rotational speeds, the V-profile tool carried low strength values compared with other profiles. Figure (7-b) is shown the welded specimens which have a flange ratio of 1.35. Trap-profile shape gave high strength than the concave profile, while V-profile was the least. Figure (7-c) is shown strength values recorded at the flange ratio 1.45. Although low strength values that were recorded at flange ratio 1.45, the highest strength value was obtained at Trap-profile. From the above, we can say that the best profile that occurs high strength value is the trapezoidal profile.

Figure 7 shows the tool profile has a noticeable influence on the strength values. The contact area (when the material volume is constant) for the trap-profile is theoretically larger than that of the concave profile or the v-profile. The heat generated by friction is proportionate to the area of contact between the work piece and the tool but the heat dissipation (loss) to the surrounding atmosphere is also proportional to the formed profile area. The consumed power divided into three parts; one of these parts goes to overcome the friction between the tool sides and the work piece, the second part is responsible to raise the temperature the third part absorbed by conventions to the surrounding atmosphere. Analysis of the heat generated and dissipated illustrate why the difference between the peak values of the two profiles are closed together (47.44 MPa and 44.22 MPa). 


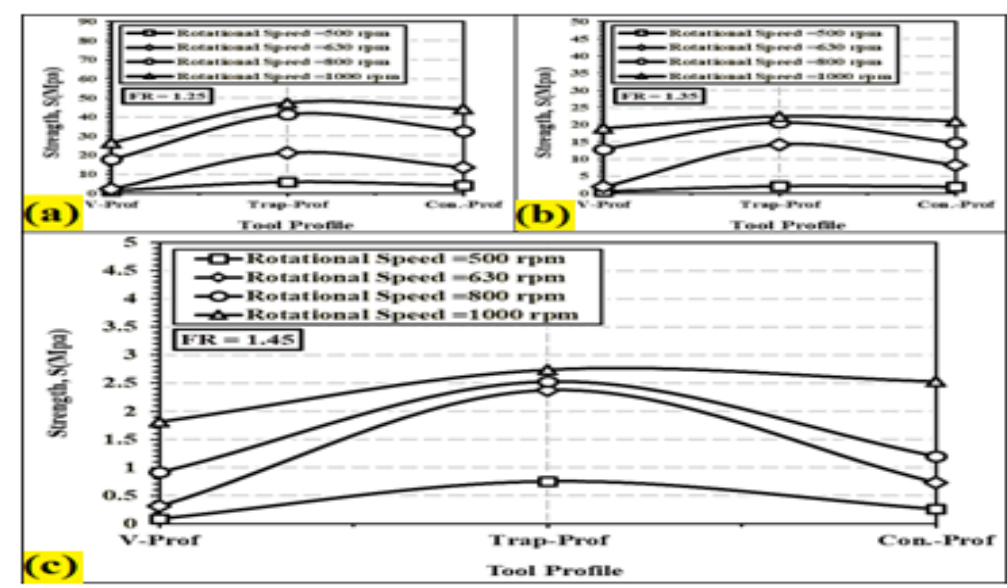

Figure 7: Effect of Tool Profile on the Joint Strength at Different Rotational Speed for (A) FR=1.25, (B) FR=1.35, and (C) FR=1.45.

\section{CONCLUSIONS}

This study presented a new welding technique for joining two parts of the tube without internal flash defect. Different welding parameters are used to evaluate the optimum welding conditions. From this work, we conclude that:

- Welding parameters tool profiles, rotational speeds, flanges ratio have a clear effect on the heat generation, and welding strength.

- The increment of rotation speed raises the welding temperature and improves the strength of welded joints.

- The trapezoidal profile gives the highest strength value when compared to other profiles.

\section{ACKNOWLEDGMENTS}

The authors wish to thank Beni-Suef University and technical staff in the faculty of Technology and Education.

\section{REFERENCES}

1. M. Merklein, M. Johannes, M. Lechner, and A. Kuppert, "A review on tailored blanks-Production, applications and evaluation," J. Mater. Process. Technol., vol. 214, no. 2, pp. 151-164, 2014.

2. U. Köklü, "Investigation into the formability of Al-1050 tailor-welded blanks with antilock braking system," Int. J. Adv. Manuf. Technol., vol. 66, no. 1-4, pp. 221-229, 2013.

3. A. Ismail et al., "The Mapping of Full Weld Cycle Heat Profile for Friction Stir Welding Pipe Butt Joints BT - Engineering Applications for New Materials and Technologies, ” A. Öchsner, Ed. Cham: Springer International Publishing, 2018, pp. 461-467.

4. F. A. Besler, R. J. Grant, P. Schindele, and M. J. R. Stegmüller, “Advanced Process Possibilities in Friction Crush Welding of Aluminum, Steel, and Copper by Using an Additional Wire,” Metall. Mater. Trans. B, vol. 48, no. 6, pp. 2930-2948, 2017, doi: 10.1007/s11663-017-1108-4.

5. F. A. Besler, P. Schindele, R. J. Grant, and M. J. R. Stegmüller, "Friction crush welding of aluminium, copper and steel sheetmetals with flanged edges,” J. Mater. Process. Technol., vol. 234, pp. 72-83, 2016, doi: https://doi.org/10.1016/j.jmatprotec.2016.03.012.

6. P. Anitha, M. C. Majumder, V. Saravanan, and Rajakumar, "Microstructural characterization and mechanical properties of friction-welded IN718 and SS410 dissimilar joint," Metallogr. Anal., vol. 7, pp. 277-287, 2018. 
7. M. Uzkut, B. S. Ünlü, S. S. Yilmaz, and M. Akdağ, “Friction welding and its applications in today's world," in Proceedings of the 2nd International Symposium on Sustainable Development, 2010, pp. 8-9.

8. D.-I. F. Zech, I. H. Cramer, D.-I. L. Appel, and M. Serve, "Orbital friction welding of metallic materials and dissimilar material joints on non-rotationally symmetrical joining cross-sections, "Weld. Testing, Mater, vol. 1, pp. 1-12, 2011.

9. V. Ebrahimzadeh, M. Paidar, M. A. Safarkhanian, and O. O. Ojo, "Orbital friction stir lap welding of AA5456-H321/AA5456O aluminum alloys under varied parameters, ”Int. J. Adv. Manuf. Technol., vol. 96, no. 1-4, pp. 1237-1254, 2018.

10. A. M. Khourshid and I. Sabry, "Friction stir welding study on aluminum pipe," Int. J Mech. Eng. Rob. Res, vol. 2, no. 3, pp. 31$339,2013$.

11. A. Ismail, M. Awang, H. Fawad, and K. Ahmad, "Friction stir welding on aluminum alloy 6063 pipe," in Proceedings of the 7th Asia Pacific IIW International Congress, Singapore, 2013, pp. 78-81.

12. G. S. Brar, M. Singh, and A. S. Jamwal, "Process Parameter Optimization of Friction Crush Welding (FCW) of AISI 304 Stainless Steel." 03-Nov-2017, doi: 10.1115/IMECE2017-71302.

13. G. S. BRAR and A. S. JAMWAL, "Friction crush Welding oF Aluminium Alloy 6061 t-6."

14. M. E. Abdullah, H. T. Elmetwally, N. G. Yakoub, M. N. Elsheikh, and A. A. Abd-Eltwab, "Effect of orbital friction crush welding parameters on aluminum tubes, ”Int. J. Sci. Technol. Res., 2020.

15. A. Sedmak et al., "Heat input effect of friction stir welding on aluminium alloy AA 6061-T6 welded joint," Therm. Sci., vol. 20, no. 2, pp. 637-641, 2016.

16. Shubhavardhan, R. N., and S. Surendran. "Friction welding to join stainless steel and aluminum materials." International Journal of Metallurgical \& Materials Science and Engineering (IJMMSE) 2.3 (2012): 5373. 

